〔Med. Entomol. Zool. Vol. 57 No. 4 p. 273-277 2006]

\title{
Detection of Japanese spotted fever rickettsiae DNA from ixodid ticks in Osumi Peninsula of Kagoshima Prefecture, Japan
}

\author{
Shinichi Noda ${ }^{1)}$ and Susumu YAmamoto ${ }^{2)}$ \\ 1) Research Center for the Pacific Islands, Kagoshima University, 1-21-24 Korimoto, Kagoshima, \\ 890-8580 Japan \\ 2) Department of Hygiene, Faculty of Medicine, Kagoshima University, 8-35-1 Sakuragaoka, \\ Kagoshima, 890-8520 Japan
}

(Received: 9 June 2006; Accepted: 4 September 2006)

\begin{abstract}
We attempted to detect Rickettsia japonica DNA from ixodid ticks by the PCR analysis. Ixodid ticks were collected at Hami, Minamikata and Shintomi of Kimotsuki Town, Kagoshima Prefecture. Ixodid ticks were also collected at three popular camp sites, Sarugajou Gorge in Tarumizu City, Kamikawaotaki Park and Shouyojunomori in Kinkou Town, Kagoshima Prefecture. A total of 3,477 ixodid ticks was collected. They were identified as four genera and eight species as follows: Haemaphysalis flava, $H$. longicornis, $H$. formosensis, $H$. hystricis, Ixodes nipponensis, $I$. ovatus, Amblyomma testudinarium and Dermacentor taiwanensis. Haemaphysalis formosensis and $H$. flava seemed to be the dominant species in the survey areas. The nucleotide sequence of PCR products with a primer pair Rj5 and Rj10 was analyzed. The nucleotide sequences of four PCR products from $H$. longicornis (one sample), $H$. formosensis (one sample) and $H$. hystricis (two samples) were successfully decided, and their sequences accorded with Rickettsia japonica DNA.
\end{abstract}

Key words: Japanese spotted fever, Rickettsia japonica, tick, Kagoshima Prefecture

\section{INTRODUCTION}

Japanese spotted fever (JSF), caused by the rickettsia, Rickettsia japonica, is a tickborne disease. In Kagoshima Prefecture, the annual incidence of JSF is currently about 10. JSF infection occurs from April to November in the Osumi Peninsula of Kagoshima Prefecture.

We observed the seasonal occurrence of ixodid ticks in the Osumi area, and attempted to detect $R$. japonica DNA from ixodid ticks by the PCR analysis (Noda et al., 2004). With a primer pair $\mathrm{Rj} 5, \mathrm{Rj} 10$, which amplifies the genomic DNA only from $R$. japonica, a 357 bp fragment was amplified from four samples of three sites; Haemaphysalis flava (three samples) and $H$. hystricis (one sample). Haemaphysalis flava and $H$. hystricis seem to be the impor- tant vector ticks for Japanese spotted fever in Kagoshima Prefecture.

JSF infection occurs widely in the Osumi Peninsula of Kagoshima Prefecture, but the eastern area of the Osumi Peninsula seems to be the main endemic area of JSF. In the present study, we collected ixodid ticks in Kimotsuki Town, and attempted to detect $R$. japonica DNA by the PCR analysis. And, the nucleotide sequence of PCR products was analyzed. Ixodid ticks were also collected at three popular camp sites in the Osumi Peninsula.

\section{Materials AND Methods}

\section{Collection of ixodid ticks}

A survey of ixodid ticks by the flagging method on vegetation was conducted in the areas where patients were suspected 


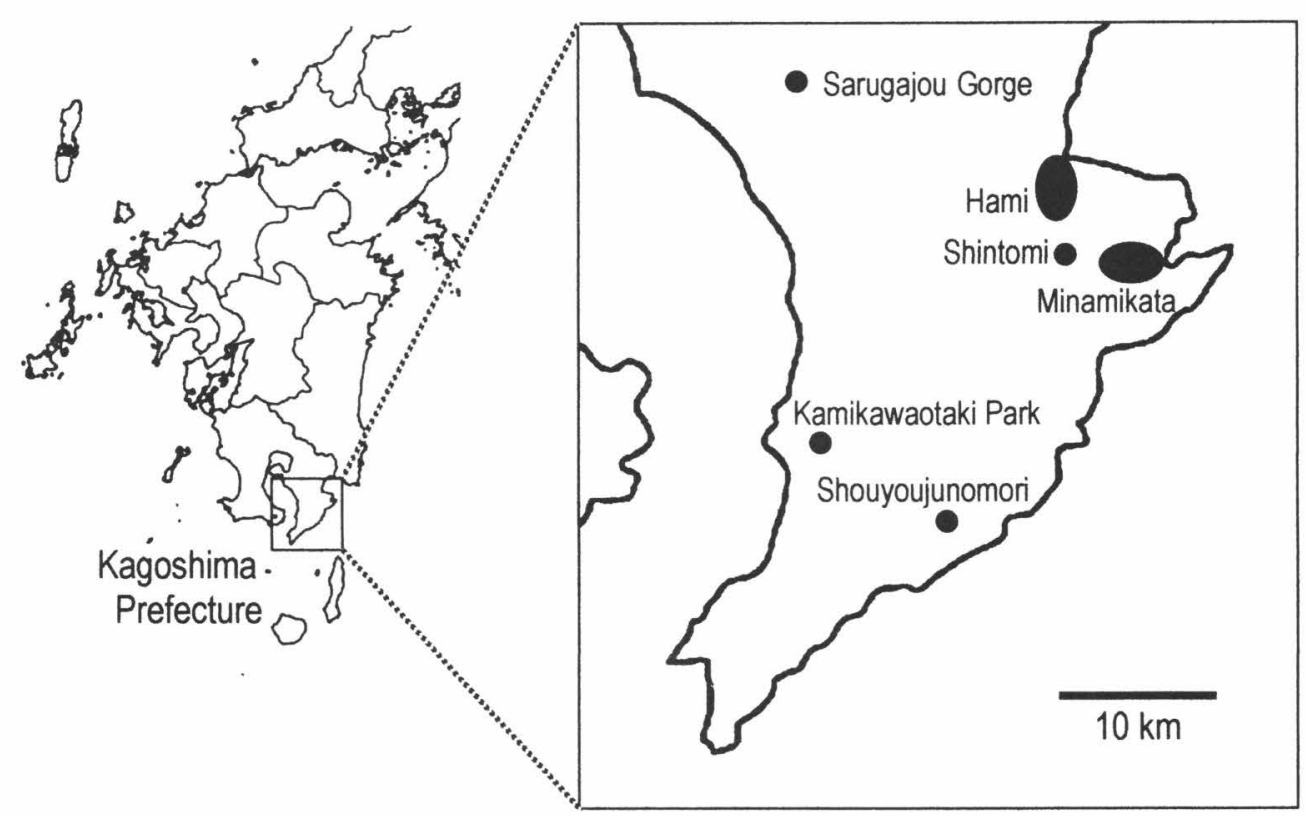

Fig. 1. Map showing survey sites in the Osumi Peninsula of Kagoshima Prefecture.

to have contracted JSF, and in popular camp sites from April 2003 to August 2005. Ixodid ticks were collected at Hami (16 sites), Minamikata (12 sites) and Shintomi (2 sites) in Kimotsuki Town, Kagoshima Prefecture. Ixodid ticks were also collected at three camp sites, Sarugajou Gorge in Tarumizu City, Kamikawaotaki Park and Shouyojunomori in Kinkou Town, Kagoshima Prefecture (Fig. 1). Adult and nymphal ticks collected were preserved in $70 \%$ ethanol until the species identification and PCR analysis. Larval ticks attached to the flag in the collection of summer were not used for PCR analysis.

Detection of Japanese spotted fever rickettsiae $D N A$

For PCR analysis, adult ticks were washed separately with distilled water. Nymphal ticks of the same species were separated into groups of ten or less, and each group of nymphs was washed with distilled water. The ticks were then cut by a heated knife, and were homogenized with $50 \mu l$ distilled water in $1.5 \mathrm{ml}$ microtubes. The suspension was mixed with
$1 / 10$ volume of $0.1 \mathrm{~N} \mathrm{NaOH}$ for incubation at $37^{\circ} \mathrm{C}$ for $1 \mathrm{hr}$. After incubation, the suspension was mixed with $1 / 10$ volume of $0.1 \mathrm{~N} \mathrm{HCl}$, and centrifuged at 2,000 $\mathrm{g}$ for 5 min (Katayama et al., 1996). The supernatant was used as the template DNA for PCR analysis.

Primers described by Katayama et al. (1996) and Furuya et al. (1995) were used for PCR analysis. The PCR amplification mixture (total volume, $50 \mu \mathrm{l}$ ) contained 10 $\mathrm{mM}$ Tris- $\mathrm{HCl}$ (pH 8.3), $1.5 \mathrm{mM} \mathrm{MgCl}_{2}, 50$ $\mathrm{mM} \mathrm{KCl}, 200 \mu \mathrm{M}$ each dNTPs, $1 \mu \mathrm{M}$ each primer, 1.25 units of Taq polymerase (TaKaRa Taq, Takara Shuzou), and $5 \mu l$ of template DNA. The gelatin was removed from the PCR amplification mixture. The thermal cycle described by Katayama et al. (1996) was used for PCR analysis. Thermal cycling (on an Astec Program Temp Control System PC-800) was performed at the following setting: $2 \mathrm{~min}$ at $95^{\circ} \mathrm{C}$ and 30 thermal cycle with $30 \mathrm{sec}$ at $94^{\circ} \mathrm{C}, 2 \mathrm{~min}$ at $57^{\circ} \mathrm{C}$ and $2 \mathrm{~min}$ at $70^{\circ} \mathrm{C}$. The same primer pair R1, R2 was used for the first and second PCR. A primer pair R1, R2 was designed for amplifying the genomic DNA from the spotted fever 
group rickettsiae and typhus group rickettsiae. The $5 \mu l$ of the first PCR product was used for the second PCR. The $5 \mu l$ of the second PCR product was used for the PCR analysis using the primer pair Rj5, Rj10. A primer pair $\mathrm{Rj5}, \mathrm{Rj} 10$ was designed for amplifying the genomic DNA only from $R$. japonica. A 357 bp fragment was amplified from the positive sample. The PCR products were electrophoresed in $1.5 \%$ agarose gels.

The PCR products containing the 300$400 \mathrm{bp}$ fragment were used for the analysis of nucleotide sequence. Template DNA was prepared by a Wizard ${ }^{\mathbb{R}}$ SV Gel and PCR Clean Up System (Promega). The nucleotide sequence of PCR products with a primer pair Rj5 and $\mathrm{Rj} 10$ was analyzed using a BigDye ${ }^{\mathbb{R}}$ Terminator v2.1 Cycle Sequencing Kit and ABI PRISM ${ }^{\circledR} 3100$ Genetic Analyzer (Applied Biosystems, USA). For the sequenced PCR, we used Rj5-2 (5' ctaccactaggagctgtttct- $\left.3^{\prime}\right)$ primer. The reaction mixture was composed of 3.2 pmol primer, $1 \mu l$ (10-40 ng) template DNA, $2 \mu l$ BigDye Sequencing Buffer and $4 \mu l$ Terminator Ready Reaction Mix in a final volume $20 \mu \mathrm{l}$. Thermal cycling was performed at the following setting: $5 \mathrm{~min}$ at $95^{\circ} \mathrm{C}$ and 30 thermal cycle with $30 \mathrm{sec}$ at $95^{\circ} \mathrm{C}, 10 \mathrm{sec}$ at $50^{\circ} \mathrm{C}$ and $4 \mathrm{~min}$ at $60^{\circ} \mathrm{C}$. Sequence similarity searches in GenBank were done with a BLAST program.

\section{RESULTS}

\section{Collection of ixodid ticks}

A total of 3,477 ixodid ticks was collected. They were identified as four genera and eight species as follows: $H$. flava, $H$. longicornis, $H$. formosensis, $H$. hystricis, Ixodes nipponensis, I. ovatus, Amblyomma testudinarium and Dermacentor taiwanensis (Table 1). Haemaphysalis formosensis was the most abundant in number $(1,899)$, followed by $H$. flava (862) and $H$. hystricis (293). Therefore, $H$. formosensis and $H$. flava seemed to be the dominant species in the survey areas.
Detection of Japanese spotted fever rickettsiae DNA

All adult and nymphal ticks collected were used for PCR analysis, and the total tube number was 993. Twenty PCR products containing the $300-400 \mathrm{bp}$ fragment were used for the analysis of nucleotide sequence. The nucleotide sequences of four PCR products were successfully decided, and their sequences accorded with $R$. japonica DNA. As shown in Table 1, the $R$. japonica DNA fragment was amplified from a sample of $H$. longicornis nymph collected at Hami, a sample of $H$. formosensis male adult collected at Hami, a sample of $H$. hystricis consisting of five nymphs collected at Hami and a sample of $H$. hystricis female adult collected at Minamikata.

\section{DiscUSSION}

At present, nine tick species, $D$. taiwanensis, $H$. cornigera, $H$. flava, $H$. formonensis, $H$. hystricis, $H$. kitaokai, $H$. longicornis, $H$. megaspinosa and I. ovatus have been confirmed to be arthropod reservoirs for R. japonica (Uchida et al., 1995; Katayama et al., 1996, 2001; Takada, 2003, 2005; Taketani et al., 2005). In our previous survey in the Osumi Peninsula, $R$. japonica DNA was detected from two species, H. flava and H. hystricis (Noda et al., 2004). Under the assumption that only one nymphal tick of the sample was infected with $R$. japonica, infection rates of $H$. flava and $H$. hystricis were $1.2 \%$ and $4.2 \%$, respectively. In the present survey, R. japonica DNA was detected from three species, $H$. longicornis, $H$. formosensis and $H$. hystricis. Estimated infection rates of $H$. longicornis, $H$. formosensis and $H$. hystricis were $0.8 \%, 0.05 \%$ and $0.9 \%$, respectively.

JSF infection occurs from April to November in the Osumi Peninsula of Kagoshima Prefecture. Seasonal occurrence of the ixodid population was surveyed at three sites of Osumi Peninsula (Noda et al., 2004). Nymphs of $H$. flava were collected throughout the year with a peak during 
Table 1. Ixodid ticks collected by the flagging method in the Osumi area of Kagoshima Prefecture.

\begin{tabular}{|c|c|c|c|c|c|c|c|c|}
\hline \multirow[b]{2}{*}{ Species } & \multirow[b]{2}{*}{ Stage } & \multicolumn{3}{|c|}{ Kimotsuki-cho } & \multirow{2}{*}{$\begin{array}{c}\text { Tarumizu City } \\
\text { Sarugajo } \\
\text { Gorge }\end{array}$} & \multicolumn{2}{|c|}{ Kinko-cho } & \multirow[b]{2}{*}{ Total } \\
\hline & & Hami & Minamikata & Shintomi & & $\begin{array}{l}\text { Shouyou- } \\
\text { junomori }\end{array}$ & $\begin{array}{c}\text { Kamikawaotaki } \\
\text { Park }\end{array}$ & \\
\hline \multirow[t]{3}{*}{ Haemaphysalis flava } & Male & 44 & 41 & 2 & & & 1 & 88 \\
\hline & Female & 45 & 53 & 3 & & & & 101 \\
\hline & Nymph & 275 & 354 & 33 & & 9 & 2 & 673 \\
\hline \multirow[t]{3}{*}{ Haemaphysalis longicornis } & Male & & & & & & & \\
\hline & Female & 2 & 4 & & & 12 & 4 & 22 \\
\hline & Nymph & $13^{*}$ & 72 & & 1 & 26 & 4 & 116 \\
\hline \multirow[t]{3}{*}{ Haemaphysalis formosensis } & Male & $72^{*}$ & 22 & 1 & 53 & 2 & & 150 \\
\hline & Female & 45 & 29 & & 67 & 2 & & 143 \\
\hline & Nymph & 879 & 675 & 33 & 16 & 3 & & 1,606 \\
\hline \multirow[t]{3}{*}{ Haemaphysalis hystricis } & Male & 37 & 18 & 3 & 8 & 2 & 10 & 78 \\
\hline & Female & 29 & $30^{*}$ & 6 & 15 & 2 & 7 & 89 \\
\hline & Nymph & $47^{*}$ & 70 & 2 & 4 & 2 & 1 & 126 \\
\hline \multirow[t]{2}{*}{ Ixodes nipponensis } & Male & & & & & & & \\
\hline & $\begin{array}{l}\text { Female } \\
\text { Nymph }\end{array}$ & 14 & 2 & & & & & 16 \\
\hline \multirow[t]{3}{*}{ Ixodes ovatus } & Male & 6 & 6 & 3 & & & & 15 \\
\hline & Female & 4 & 4 & & & & & 8 \\
\hline & Nymph & & & & & & & \\
\hline \multirow[t]{3}{*}{ Amblyomma testudinarium } & Male & 2 & & & & & & 2 \\
\hline & Female & & 1 & & & & & 1 \\
\hline & Nymph & 79 & 48 & 4 & 104 & 5 & & 240 \\
\hline \multirow[t]{3}{*}{ Dermacentor taiwanensis } & Male & 1 & & & & & & 1 \\
\hline & Female & & 2 & & & & & 2 \\
\hline & Nymph & & & & & & & \\
\hline Total & & 1,594 & 1,431 & 90 & 268 & 65 & 29 & 3,477 \\
\hline
\end{tabular}

* Including each one sample which was positive for $R$. japonica DNA fragment. 
the period between March and May. A large number of adults was collected from February to April but not in August and September. On the other hand, nymphs and/or adults of $H$. longicornis and $H$. hystricis were collected from April to September. The present data may suggest that $H$. longicornis and $H$. hystricis are important vector ticks in Kagoshima Prefecture.

A man and his wife were infected with JSF at the same time in July 2003 at a camp site, Sarugajou Gorge in Tarumizu City. Therefore, ixodid ticks were also collected at three popular camp sites containing Sarugajou Gorge, but $R$. japonica DNA was not detected from ixodid ticks. In the present survey, $R$. japonica DNA was detected from one female $H$. hystricis collected at the site of Minamikata. This site was located at the top of a hill, Kanodake (87 $\mathrm{m}$ above sea level), which adjoins a residential area. Eight cottages were constructed on the hill, and families and young peoples enjoy outdoor amusements. There is a possibility that not only inhabitants near the camp sites but also visitors to the camp sites from nonendemic areas contact JSF. In the JSF cases of the man and wife, they lived in the northwestern area of Kagoshima Prefecture and visited a camp site of Sarugajou Gorge.

Haemaphysalis longicornis and $H$. hystricis seem to be important vectors of JSF in Kagoshima Prefecture. Of these tick species, the vectors for JSF rickettsia to humans may consist of a complex of dominant tick species parasitic to humans. Further studies on tick fauna and rickettsial agents are indispensable in determining the role played by each possible vector.

\section{ACKNOWLEDGEMENTS}

This work was carried out as part of
Kagoshima University Emerging Disease Countermeasures Project financially supported by President Discretionary Fund of Kagoshima University.

\section{REFERENCES}

Furuya, Y., Katayama, T., Yoshida, Y. and Kaiho, I. 1995. Specific amplification of Rickettsia japonica DNA from clinical specimens by PCR. J. Clin. Microbiol., 33: 487-489.

Katayama, T., Furuya, Y., Inada, T., Hara, M., Yoshida, Y., Imai, M., Itagaki, A. and Chiya, S. 2001. Detection of spotted fever group rickettsiae DNA from ticks in Kanagawa, Shimane and Kochi Prefecture. J. Jpn. Assoc. Infect. Dis., 75: 53-34 (In Japanese).

Katayama, T., Furuya, Y., Yoshida, Y. and Kaiho, I. 1996. Spotted fever group rickettsiosis and vectors in Kanagawa Prefecture. J. Jpn. Assoc. Infect. Dis., 70: 561-568 (In Japanese with English summary).

Noda, S., Yamamoto, S. and Honda, T. 2004. Detection of Japanese spotted fever rickettsiae DNA from ixodid ticks and seasonal occurrence of ixodid tick population on the Osumi Peninsula, Kagoshima Prefecture. Med. Entomol. Zool., 55: 2128.

Takada, N. 2003. Vectorial competences and distributional patterns of parasitic acari, especially for emerging diseases in Japan and East Asia. Med. Entomol. Zool., 54: 1-12 (In Japanese with English abstract).

Takada, N. 2005. Epidemiology of rickettsioses in Southeast Asia, especially on geopathological aspects. Antibiotics \& Chemotherapy, 21: 845-852 (In Japanese).

Taketani, T., Yasuda, K. and Yamaguchi, S. 2005. Japanese spotted fever. Antibiotics \& Chemotherapy, 21: 831-838 (In Japanese).

Uchida, T., Yan, Y. and Kitaoka, S. 1995. Detection of Rickettsia japonica in Haemaphysalis longicornis ticks by restriction fragment length polymorphism of PCR product. J. Clin. Microbiol., 33: 824828. 